\title{
A educação física na saúde mental: construindo uma formação na perspectiva interdisciplinar
}

Odilon José Roble ${ }^{1}$

Maria Inês Badaró Moreira²

Fernanda Baeza Scagliusi ${ }^{3}$

\section{Introdução}

O Ministério da Saúde (MS) promove a estruturação da rede de cuidados para o acolhimento do sofrimento psíquico na comunidade. Dentre os equipamentos desta rede, o Centro de Atenção Psicossocial (CAPS) insere-se como articulador das ações que envolvem os portadores de sofrimento psíquico em um território, atendendo aos postulados de acessibilidade e equidade.

Com a regulamentação da Lei no. 10.216 (Brasil, 2001), testemunhamos avanços na reorganização dos serviços públicos (Brasil, 2005, 2004). Em 2010, existia uma rede com 1.531 CAPS, em todos os Estados (Brasil, 2010). Na direção da integração das ações de saúde mental às demais ações de saúde, a rede de atenção em saúde mental deve articular diversos equipamentos de saúde (Brasil, 2004). Neste sentido, o CAPS equipamento tornou-se um ponto primordial de apoio dos portadores de sofrimento psíquico grave.

Na medida em que o processo de desinstitucionalização requer uma mudança da relação social com a loucura, o campo da saúde mental é permeado por conflitos e contradições, evidenciados em transformações para os usuários, seus familiares e a comunidade.

Tais mudanças incidem, também, sobre os profissionais envolvidos nesta nova maneira de cuidar. A compreensão dessa forma de (re)apropriar é fundamental, pois trata-se de uma tentativa de se compreender como as pessoas que vivenciam a condição de sofrimento psíquico ressignificam sua condição de existir em comunidade, por meio da "produção de vida, de sentido, de sociabilidade, a utilização dos espaços coletivos de convivência dispersa" (Rotelli, 1990, p.30). Esta concepção inaugura um novo campo de trabalho para diversos profissionais. Este trabalho deve levar à produção de um novo tipo de subjetividade, que permita a manifestação sem interditar sua expressão; uma clínica que não retenha o indivíduo em um jogo institucional ou o (re)tome como objeto, desconsiderando-o como sujeito. Assim, confirma-se a desinstitucionalização como estratégia para a instituição inventada (Amarante, 2000).

Convocados por Basaglia (1985), sob o lema "a liberdade é terapêutica", os trabalhadores da saúde, então protegidos pelo limite de suas especialidades, se viram diante do desafio de rever a forma como compreendiam e atuavam frente

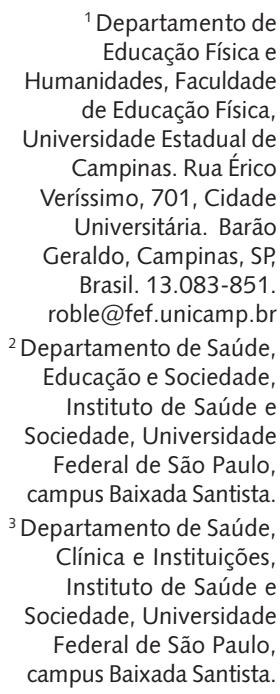


às necessidades de saúde do indivíduo com sofrimento psíquico intenso.

Consequentemente, diversos profissionais foram convocados a participar do campo da saúde mental, uma vez que a compreensão deste fenômeno e o trabalho em saúde passaram a requerer um olhar integral para os usuários dos serviços. Um desses profissionais foi o educador físico. Entretanto, a inserção desse profissional nesse campo é uma construção de um saber/fazer, já que esta é uma profissão sem tradição na área e cuja contratação não é obrigatória. Ademais, a maioria das pesquisas acerca da relação entre atividade física e saúde mental foca em uma perspectiva biomédica, investigando efeitos da atividade física sobre parâmetros de saúde mental. Assim, pouco se discute acerca das concepções, ações e possibilidades do educador físico nessa área (Wachs, Fraga, 2009). Para iniciarmos essa discussão, é importante retroceder e investigar: como o corpo e o movimento - objetos fundamentais da Educação Física - se relacionam com a loucura?

\section{Corpo, racionalismo e saúde mental na tradição do pensamento ocidental}

A divisão do homem em corpo e mente tornou-se lugar comum no pensamento das sociedades ocidentais. Uma hierarquia foi estabelecida, colocando-se o corpo como subordinado à mente, o sensível como inferior ao inteligível, e a experiência como menos válida que a razão. Esse processo de configuração do pensamento ocidental é denominado racionalismo (Separavich, Canesqui, 2010). O racionalismo tem uma de suas pedras fundamentais em Sócrates ${ }^{4}$. O "conhece-te a ti mesmo" socrático não está fundamentado na experiência sensível, nem na compreensão da pessoa entre seus semelhantes, trata-se, fundamentalmente, de extrair a verdade do interior do ser, dando à luz novas ideias, em processo semelhante ao da parteira. Por isso, o método socrático chamava-se "maiêutica", palavra que designa a arte da parteira. Na filosofia socrática, a maiêutica se refere a essa suposta capacidade do filósofo de extrair a verdade do interior intelectivo dos seres. Assim, o saber socrático é racionalista na medida em que nada deve ao corpo, mas apenas aos ditames da razão e à capacidade de obter o conhecimento a partir do raciocínio abstrato.

Essa forma de pensar, que marcou profundamente toda a tradição posterior do pensamento ocidental, além de apartar corpo e mente, estabeleceu tamanha hegemonia da razão que o corpo, não raro, passou a ser entendido até como um obstáculo para o desenvolvimento das condições intelectuais. Leiamos Platão nesse sentido ${ }^{5}$ :

Mas o que diremos das aquisições da inteligência? O corpo é ou não é um obstáculo, quando se associa com esta análise? Vou tornar a questão mais clara com um exemplo. Os olhos e os ouvidos transmitem alguma verdade, ou os poetas têm razão em repetir sem cessar que, em verdade, nada ouvimos nem nada vemos? Visto que, se estes dois sentidos são inseguros, então, os outros o serão ainda mais, uma vez que são inferiores a eles. (Platão, 1999, p.26)

Ao duvidar de que os sentidos sejam capazes de produzir alguma verdade, apenas o intelecto fica responsável por gerar um saber válido. Subsequentemente, supõe-se que a atenção aos sentidos do corpo pode, até mesmo, levar à insanidade, como deduzimos das passagens seguintes:

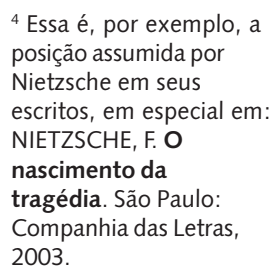

\footnotetext{
${ }^{5}$ Trata-se do diálogo

"Fédon", escrito por

Platão no século III a.C.
} 
Há algum sentido corporal por meio do qual chegaste a apreciar as coisas de que te falo, como a nobreza, a sanidade, a força, em resumo, a essência de todas as coisas? (...) conseguirá mais claramente [conhecer] quem examinar as coisas apenas com o pensamento (...) completamente isolado do corpo, que apenas transtorna a alma e impede que encontre a verdade. (...) nada é mais certo do que isso: o corpo nunca nos conduz a algum pensamento sensato. Não, nunca!. (Platão, 1999, p.27)

Para a tradição do pensamento posterior, que tem em Sócrates e Platão alicerces sólidos, dos quais se nutrem também a medicina e a ciência, é decorrente supor que o homem que tiver comprometida a sua racionalidade, perderá a capacidade de conhecer, como também a dignidade do seu ser. Se o homem é, tal qual a definição de Aristóteles, um "animal racional", ao ter sua racionalidade comprometida, o que resta ao homem? A animalidade de seu corpo.

No projeto da modernidade, em que a razão passa por sistemática revisão, o corpo permanece como empecilho ao conhecimento verdadeiro. Submetido à "coisa extensa" (res extensa), em oposição à "coisa pensante" (res cogitans) que é a mente, o corpo não resiste à sistemática da dúvida cartesiana. Segundo Maffesoli (2001), o cartesianismo é regido por um "voluntarismo racional", do qual o corpo não tem como participar por conta de suas sensibilidades e instintos. Para que conclamemos novamente o corpo no processo de conhecimento, seria preciso eleger uma razão sensível (Maffesoli, 2001) ou uma "razão corporal fundamentada nas paixões" (Onfray, 2006, p.68).

Tais esforços estariam na contramão dessa tradição racionalista, antiga e moderna, porém, encontrariam suportes em saberes do próprio pensamento ocidental, em filosofias vitalistas ou, até mesmo, em correntes racionalistas que não negaram o papel do corpo. Há vozes que repensaram esses cenários, tais como Espinosa, Schopenhauer, Nietzsche ou Merleau-Ponty. Vem da ética de Espinosa uma sólida relação de indissociabilidade entre corpo e alma, na qual a experiência é fator decisivo, pois "a alma humana é apta a perceber um grande número de coisas, e é tanto mais apta quanto o seu corpo pode ser disposto de um grande número de maneiras" (Espinosa, 1992, p.220).

Já Nietzsche (2003) reestrutura a definição de ser humano proposta por Aristóteles. Para Nietzsche, inspirado por Schopenhauer, o homem não é um "animal racional", mas, sim, um "animal não-determinado". A qualidade dessa determinação vem da experiência com o outro e com a cultura. Por sua vez, Merleau-Ponty afirma que "os sentidos dos gestos não são dados mas compreendidos pelo espectador". Assim, a compreensão do gesto é obtida pela "reciprocidade entre minhas intenções e os gestos do outro", o que o faz concluir que "tudo se passa como se a intenção do outro habitasse meu corpo ou se como minhas intenções habitassem o seu" (Merleau-Ponty, 1994, p.251). São por essas definições e suas consequentes aplicações que pretendemos conduzir as reflexões sobre o corpo e o movimento no cenário do sofrimento psíquico. Essa não-determinação, que é apresentada por Nietzsche, e a complementaridade entre gestos e intenções, revelada por Merleau-Ponty, são matrizes de nossas diferenças, que nos conferem o poder da pluralidade, da liberdade e da adaptação. Nossos corpos e nossos gestuais são semelhantes, mas, uma vez humanos, são igualmente não determinados, pois o uso que fazemos do nosso corpo atende, parcialmente, aos preceitos da vontade. Esse é um ponto de partida 
para a compreensão do movimento como uma das mais importantes experiências para o ser humano. Para Sheets-Johnstone (2010), não é a finalidade ou o instinto, mas as "regras não escritas da cultura" que determinam a estrutura final dos gestos humanos.

Por esse caminho da "não-determinação" é que o corpo e o gesto são fontes de saberes, tanto pelo interesse em se compreender que "determinações" foram dadas a eles, como para se propor novas "determinações". Fica claro, portanto, a possibilidade de ações terapêuticas relacionadas ao corpo e ao movimento. É nesse cenário que vislumbramos a pertinência do educador físico, e é nessa perspectiva que o artigo objetiva relatar e analisar uma experiência acerca da formação do educador físico como profissional de saúde mental, inserido em uma equipe interdisciplinar. Enquanto Wachs e Fraga (2009) relataram como o educador físico desenvolve um trabalho em saúde mental no CAPS, o presente estudo mostra a aproximação de estudantes de Educação Física desse cenário, na tentativa de identificar possibilidades de formação e atuação.

\section{Métodos}

As atividades ocorreram dentro um módulo curricular que é comum aos cursos do campus Baixada Santista da Universidade Federal de São Paulo. Trata-se do Módulo de Clínica Integrada: produção do cuidado, cujos objetivos compreendem: ampliar as competências para o trabalho em equipe, a atenção integral em saúde, e o diálogo interprofissional na produção do cuidado; realizar intervenções em comum na produção do cuidado; exercitar a elaboração e implantação de projetos terapêuticos, e conhecer a organização da rede de serviços em saúde. Alunos de terceiro ano dos cursos de Psicologia, Nutrição, Terapia Ocupacional, Fisioterapia e Educação Física formam equipes, que, junto com os docentes de tais cursos, desenvolvem projetos terapêuticos em serviços de saúde de Santos.

A experiência ocorreu durante o segundo semestre de 2009, no qual duas equipes de alunos desenvolveram atividades, junto com os docentes, em um NAPS de Santos, cidade que apresentou papel importante na reforma psiquiátrica (Luzio, L'abbate, 2006). Este NAPS apresenta enfermeiros, assistentes sociais, médicos, farmacêuticos, psicólogos e terapeutas ocupacionais. Ele fornece serviço de hospital-dia (HD), que atende, geralmente, de 15 a quarenta usuários. Cada equipe permaneceu no serviço por seis semanas e foi composta por: um aluno de Educação Física, um aluno de Fisioterapia e dois alunos dos cursos de Psicologia, Nutrição e Terapia Ocupacional.

No primeiro encontro, os alunos conheceram o serviço e interagiram com a equipe e os usuários do HD. Os três encontros seguintes consistiram em atividades que visavam a formação de vínculo e a identificação das demandas dos usuários. A partir das observações iniciais, foi elaborado um projeto terapêutico, que foi desenvolvido ao longo dos encontros, que seguiam este formato: a) conversa entre docentes e alunos, para organizar a atividade do dia; b) realização da atividade pelos alunos, sob supervisão docente; c) reunião de supervisão, com participação dos alunos, docentes e da equipe do serviço.

A coordenadora do Naps sugeriu ações que tornassem o ambiente ainda mais acolhedor e que aumentassem o número de atividades oferecidas aos usuários do HD. Cabe ressaltar que o serviço já dispunha de várias atividades, como caminhada, teatro do oprimido, assembleias, oficinas de artesanato, entre outras, e que, portanto, a lógica do nosso trabalho seria a de complementar tais atividades. Os alunos observaram que alguns usuários apresentavam alterações posturais e de percepção corporal. Por parte dos professores, foram sugeridas ações que desenvolvessem, nos alunos, a escuta e a formação de vínculo; dispositivos relevantes para a clínica comum e a produção de cuidado (Benevides et al., 2010).

Dessa forma, foram realizadas:

- Oficinas: culinária, degustações, desenho, pintura e origami.

- Musicoterapia.

- Exercícios de alongamento e de relaxamento.

Os alunos de Educação Física participavam de todas as atividades, porém, também mobilizavam os usuários para o encontro, por meio da roda de alongamento, que era sempre conduzida no início da 
atividade. O alongamento foi escolhido por todos poderem desempenhá-lo e porque os usuários apresentavam problemas de postura e flexibilidade.

Os alunos elaboraram diários individuais de campo, um projeto terapêutico e o relatório final. Foram destacados os trechos do projeto terapêutico e do relatório mais significativos e pertinentes à discussão sobre o campo da Educação Física. Subsequentemente, eles foram agrupados segundo tema-chave (que emergiram a partir dos assuntos mais prementes em cada discurso), interpretados e discutidos. Tal categorização foi feita por um pesquisador, revista pelos demais e discutida por todos, havendo consenso sobre a mesma. Tratou-se de uma coleta de dados de natureza qualitativa, na qual os pesquisadores interpretaram os resultados de modo a produzirem um ensaio reflexivo, ou seja, uma opção que não confere aos dados o status de fonte documental. Tal opção nos aproxima de métodos qualitativos e filosóficos, tais como o genealógico, ou o filosófico-conceitual (Martins, 2004), ou a cartografia (Kastrup, 2007).

\section{Resultados e discussão - sobre o novo profissional da saúde: elasticidade e movimento}

A partir dos trechos destacados do material de análise, foram identificados três temas-chave: 1) tendência ao sedentarismo entre os usuários; 2) aprendizado mútuo e significativo, e 3) possibilidades de atuação para o educador físico.

Os seguintes trechos foram identificados como pertencentes ao tema "tendência ao sedentarismo entre os usuários":

"Os usuários se queixam de dores musculares, em virtude do número de horas que passam sentados".

Tal percepção gerou inquietude nos estudantes de Educação Física, que identificaram uma possibilidade de atuação voltada à diminuição do sedentarismo, como se constata neste discurso:

\footnotetext{
"No tocante à Educação Física, há muito o que ser trabalhado com essa população, que é extremamente sedentária. Nessa unidade, e em muitas outras, há a falta do educador físico, o que demonstra as sérias barreiras para a inserção deste nos meios de saúde".
}

Uma das atividades oferecidas pelo serviço é a "caminhada no Horto", na qual os usuários andam no Horto Florestal e realizam uma roda de conversa ao final. Para diminuir o sedentarismo, atividades como esta poderiam ser intensificadas.

O tema "aprendizado mútuo e significativo" foi observado nos trechos a seguir:
"Pudemos observar no decorrer dos encontros muitas evoluções. Os usuários se fortaleceram como grupo, houve uma maior participação nas atividades, eles conseguiam falar mais sobre suas dificuldades pessoais, adquiriram uma melhor percepção corporal e depositaram confiança no nosso grupo".

O discurso a seguir ilustra como a prática apresenta a questão do dualismo mente e corpo, descrito brevemente na introdução deste trabalho:

\footnotetext{
"Eu, que sempre achei que minha formação fosse baseada no todo, sem dicotomia mente e corpo, na melhor visão holística do ser humano, fui surpreendida ao ver que quando pedíamos 'estique o braço', a maioria dos usuários não conseguia. Então, trabalho em saúde mental é entender que o que está desorganizado por dentro reflete totalmente no próprio corpo. E organizar as pessoas não está nem perto de propor exercícios intelectuais, no plano das ideias, nas dimensões do abstrato. É preciso que seja concreto. Jamais pensei em fazer
} 
exercícios de coordenação para usuários do NAPS. Mas se por um lado eu vi a incrível confusão que uma usuária fez ao tentar esticar o braço, por outro eu vi o quanto foi fácil para ela descascar e amassar uma banana. Talvez até os exercícios físicos possam cair no plano do abstrato".

Tais trechos exemplificam a riqueza trazida pela vivência no serviço para a formação dos alunos. Já o tema "possibilidades de atuação para o educador físico" foi assim identificado:

\begin{abstract}
"O educador físico não deixa de lado seu título quando exerce atividades que não estejam diretamente associadas às práticas da Educação Física. O profissional que trabalha no NAPS, acima de tudo, é um profissional de saúde mental".
\end{abstract}

"A reinserção completa do indivíduo na sociedade também depende de uma melhora do seu próprio organismo, pois, com a melhora da sua aptidão física, ele depende menos do próximo para a realização das atividades da vida diária".

“Inúmeras atividades específicas e protocoladas da área de Educação Física poderiam ser realizadas no contexto do NAPS, conquanto essas ações teriam um cunho biomédico forte, sem menosprezar a importância das mesmas. As ações físicas com caráter psicossocial deveriam estar em pauta e ser priorizadas no âmbito da reinserção social dos usuários".

Os três discursos supracitados ilustram a problemática central dos estudos acerca do corpo: como pensar pelo corpo? Sabe-se que a fala do corpo está ligada à fala da identidade, e que o corpo constitui uma amálgama de processos biológicos, materiais, subjetivos, históricos e socioculturais. Entretanto, sabe-se que o entrave para se pensar pelo corpo passa pela dificuldade de se interligarem tais perspectivas, que são tidas como entidades separadas (Blackman, 2008). Nossos resultados mostram que é possível pensar pelo corpo por meio da experimentação e da ação livre e criativa. Tais discursos (e, também, o discurso do tema "aprendizado mútuo e significativo", referente à " necessidade da ação concreta") apresentam similaridades com a premissa do corpo como pulso, que propõe uma clínica constituída e balizada pelo corpo, na qual, por meio do encontro, os corpos se estendem e se conectam com outros corpos e práticas, que, subsquentemente, constituem novas possibilidades corporais e novos significados acerca do que é ser humano (Liberman, 2010). É nesse contexto que se faz relevante um método fenomenológico, tal como sugere Maffesoli (2001), balizado pela descrição, intuição e metáfora. Para pensar pelo corpo, no lugar de uma razão abstrata, propõe-se a atenção à experiência, por isso, a descrição. No lugar de uma verdade calculada pelas premissas, um saber sentido pela intuição. Em vez de uma compilação de resultados objetivos, o horizonte aberto dos discursos e das metáforas. O método corporal e fenomenológico é menos conclusivo e mais propositivo, abrindo as portas da reflexão. Talvez, por isso, Merleau-Ponty asseverasse que a carne "não é matéria, não é espírito, não é substância. Seria preciso, para designá-la, o velho termo elemento, no sentido em que era empregado para falar-se da água, do ar, da terra e do fogo" (Merleau-Ponty, 1992, p.135).

Sobre o efeito do alongamento no grupo, ao longo das semanas:

\footnotetext{
"Na terceira semana, algumas pessoas já sabiam exatamente os movimentos necessários. A coordenação de algumas pessoas já estava visivelmente melhorando. O alongamento, além de exercitar os músculos e relaxar, garante que os usuários dispensem um pouco mais de energia nas tarefas seguintes. O alongamento trazia ânimo ao grupo. Na quarta semana, ao invés do aluno de Educação Física demonstrar cada movimento, ele perguntava ao grupo qual exercício eles se lembravam e conforme eles iam lembrando a atividade acontecia. Além de contribuir para a fixação dos movimentos, deixar que os usuários comandem em conjunto conosco as atividade pode promover a auto-estima e aumentar a confiança deles neles mesmos e em nós, o que facilita a criação de um vínculo".
} 
Constatamos que, mais do que os benefícios diretos proporcionados pelo alongamento, essa roda inicial configurava-se como um rito de começo dos trabalhos, nos quais uma prontidão se desenvolvia nos usuários. Sheets-Johnstone (2009, p.17) cita um ensaio de Daniel Stern no qual este afirma que "when the world is too much with us, the body ransoms us". Este é um ponto de partida para a autora inferir que o corpo tem, hoje, um papel central no reencontro do homem consigo mesmo e com o mundo. Uma proposta aparentemente simples de alongamentos pode se contrapor ao peso que o mundo depositou sobre o homem, em especial, quando acometido de sofrimento psíquico. Para esse homem acuado em seu sofrimento, alongar-se, ampliar seu corpo, preencher novos espaços, ir além da mobilidade básica, cada vez mais retesada pelo peso do mundo, pode representar uma ação de luta, uma alavanca na reconstrução de si.

\footnotetext{
"Pude trabalhar na Educação Física, atuando com pessoas diferentes, e percebendo o quão importantes são a minha profissão e o meu conhecimento. Pude entender a verdadeira missão do trabalhador em saúde, que consegue fazer uma grande diferença para os pacientes mesmo por meio de gestos e atividades simples, o que me deu grande satisfação. Assim percebi que a área de Educação Física é tão importante quanto a Psicologia, Fisioterapia, Terapia Ocupacional e a Nutrição para esses pacientes. Entendi que a saúde mental depende da saúde física também, pois o equilíbrio entre corpo e mente é necessário. Assim, pude reconhecer o papel da Educação Física na saúde mental, sem preconceitos e percebendo a importância da minha futura profissão".
}

Tal fala é corroborada por Merhy (1998), que propõe que, para se produzir cuidado em saúde, devem-se empreender esforços no sentido de desconstruir o agir profissional pautado em áreas delimitadas e especializadas, pois o cuidado é uma experiência de (re)invenção da saúde como bem público e como potência de luta a serviço da vida individual e coletiva. Além disso, percebe-se que estar no serviço de saúde e aprender com ele é uma experiência extremamente rica para a formação.

Se começamos essa pesquisa identificando a polissemia inerente ao tema da saúde mental e optamos por um método qualitativo no intuito de tentar absorver, ao máximo, a diversidade de sentidos decorrentes da experiência, notamos que nossos resultados são expressão dessa complexidade. Não que, com isso, estejamos frente a um fenômeno incapaz de ser circunscrito a qualquer inteligibilidade, contudo, o que nossos resultados evidenciaram está, sem dúvida, além da relação primária de causa e efeito. O sofrimento psíquico parece implantar-se como um hiato no meio dessa relação, apresentandonos o inesperado, o imponderável e o de difícil classificação. Mas, ainda assim, nossas observações mostram que a ação terapêutica dialoga com esse imponderável. Parece, assim, destituída de uma função messiânica na qual os Educadores Físicos seriam, entre outros, os profissionais da "libertação" de tal paciente. Diferente disso, o Educador Físico aparece como um interlocutor nesse diálogo terapêutico, mais especificamente, alguém que veio conversar sobre o corpo ou com o corpo desse ser humano. Talvez resida aqui a riqueza dos resultados obtidos, pois eles indicam a importância terapêutica singular do Educador Físico, em especial, quando participante de equipes interdisciplinares. Diferentemente de pesquisas nas quais os achados confirmam hipóteses previamente enunciadas, nossos resultados, ainda que corroborem a importância já aventada do profissional de Educação Física nesse contexto, descortinam, também, novos horizontes para tal prática.

\section{Considerações finais}

O trabalho de desinstitucionalização pretende-se revolucionário, no sentido de uma utopia concreta, como aquela pela qual lutou Basaglia (1982), porque qualquer cidadão pode viver junto com outro. Uma utopia que se mostrou por meio da prática e das trocas cotidianas, que pode ser construída na forma de conviver com o outro, em um modo de produzir novos sentidos para a vida que não depende da tutela profissional. 
Consideramos que o espaço de formação que se insinua no cenário apresentado não pode ser limitado a ensinamentos de novas tecnologias de como cuidar, mas refere-se a uma postura existencial de abertura para o novo e de aceitação do outro: inaugurar-se em um pensar/fazer que nenhuma teoria abarca. Essa prática poderá insinuar-se na vivência das diversas situações em que os profissionais se permitam ser provocados e impulsionados para outro lugar do saber/fazer, no qual nunca estiveram antes.

Nesse sentido, podemos pensar em todos os encontros que forjam um profissional da saúde, que temos em alguns momentos vida afora: quando lemos um livro, assistimos a uma peça, ouvimos uma música, apreciamos uma obra de arte, trocamos um dedo de prosa, nos interessamos pelo outro, nos atentamos por pessoas que vimos passar. Ou seja, quando nos permitimos tirar os olhos da nossa vida e os dirigirmos para fora de nós.

São encontros que guardam o mistério do imprevisível, que devem ser apreciados, e não engolidos; é algo indescritível, sentido em todo o corpo, saboreado: "[...] nem sei explicar estas coisas... um sentir é do sentente, mas o outro é do sentidor" (Guimarães Rosa, 2001, p.328).

Ao nos inserirmos no campo da saúde mental, sentimo-nos provocados a pensar/sentir de um modo diferente, empurrados para sairmos de nossas casas (campos de conhecimento) feitas de pedra, para nos arriscarmos em alguma outra feita de palha, sairmos de nossas certezas, para experimentarmos o sentido do acaso nos encontros. Lançar-nos ao acaso é também transformar nossas angústias paralisantes em uma força potencializadora por meio da coragem de correr risco, pois, para atuar nesta área, "é preciso ter coragem".

Por isso, trabalhar em saúde mental é dar-se o trabalho de transformar o cotidiano com a força daquilo que se acredita. Isto é, desalojar certa concepção de fazer que pretende constituir-se como modelo. É subverter um modelo de pensamento herdado com base em uma racionalidade em busca de técnicas e fórmulas prontas. Isso pode ser desconfortável para a maioria dos profissionais de saúde e das teorias sobre o cuidado e a clínica neste campo, pois implica romper com modelos e protocolos.

Convoca-nos a avançar em termos teóricos e a apontar uma nova concepção do fazer em saúde e do existir no cotidiano da vida.

A Educação Física também já esteve fortemente amarrada pelo racionalismo, traduzido, sobretudo, pelo seu apego ao tecnicismo e pela prática da atividade física destituída de reflexão. Entretanto, desde as últimas décadas, a produção de conhecimentos em Educação Física refuta uma condição de mera reprodutora e lança seus profissionais em novos campos de atuação. Em um universo como o da saúde mental, no qual razão e sensibilidade, mente e corpo são polos tensos e intensos, o educador físico tem muito a aprender e, ainda, bastante a contribuir. Experiências como as relatadas por Wachs e Fraga (2009) e, também, essa, agora apresentada, são pequenos passos nessa nova estrada.

Acreditamos na formação dos novos profissionais convocados para o trabalho em saúde e apostamos naqueles que sabem que têm uma vida a ser dita e vivida, que deve ser questionada, debatida, afetada, refletida. É nesse contexto que o educador físico se insere, podendo contribuir e ampliar as possibilidades de intervenção. Reivindicamos que os serviços de saúde se transformem, também, em espaços de encontros ricos de trocas e de produção de um novo, e não de repetições do que já está dado. Somos todos interlocutores, em busca de encontros que nos façam vibrar e que nos transformem. Nossa preocupação, ao findarmos este trabalho, é com a formação de uma postura reflexiva que impulsione a avançar sobre seus próprios conteúdos e práticas. Mais movimento e plasticidade é o que desejamos a todos nós!

\section{Colaboradores}

Os autores trabalharam juntos em todas as etapas de produção do manuscrito. 


\section{Agradecimentos}

Os autores agradecem aos alunos que protagonizaram a experiência descrita; aos docentes do Eixo Trabalho em Saúde da Universidade Federal de São Paulo, campus Baixada Santista; à Coordenadoria de Saúde Mental do município de Santos; à coordenadora e aos profissionais do Naps.

\section{Referências}

AMARANTE, P.D.C. O homem e a serpente: outras histórias para a loucura e a psiquiatria. Rio de Janeiro: Fiocruz, 2000.

BASAGLIA, F. Psiquiatria alternativa: contra o pessimismo da razão, o otimismo da prática. São Paulo: Brasil Debates, 1982.

. A instituição negada: relato de um hospital psiquiátrico. 3.ed. São Paulo: Graal, 1985.

BENEVIDES, D.S. et al. Cuidado em saúde mental por meio de grupos terapêuticos de um hospital-dia: perspectivas dos trabalhadores de saúde. Interface - Comunic., Saude, Educ., v.14, n.32, p.127-38, 2010.

BLACKMAN, L. The body: the key concepts. New York: Berg, 2008.

BRASIL. Ministério da Saúde, Secretaria de Atenção à Saúde, Departamento de Ações Programáticas e Estratégicas, Coordenação de Saúde Mental, Álcool e Drogas. Saúde Mental em dados 7, v.5, n. 7, p. 7. Brasília: Ministério da Saúde, 2010.

- Ministério da Saúde, Secretaria de Atenção à Saúde, Coordenação Geral de Saúde Mental. Reforma psiquiátrica e política de saúde mental no Brasil. Documento apresentado à Conferência Regional de Reforma dos Serviços em Saúde Mental: 15 anos depois de Caracas. Brasília: OPAS, 2005.

Ministério da Saúde, Secretaria de Atenção à Saúde, Coordenação Geral de Saúde Mental. Saúde Mental no SUS: os Centros de Atenção Psicossocial. Brasília: Ministério da Saúde, 2004.

Congresso Nacional. Lei n. 10.216, de 6 de abril de 2001. Dispõe sobre a proteção e os direitos das pessoas portadores de transtornos mentais e redireciona o modelo assistencial em saúde mental. Diário Oficial da União, Brasília, DF, 9 abr. 2001.

ESPINOSA, B. Ética. Lisboa: Relógio D'água, 1992.

KASTRUP, V. O funcionamento da atenção no trabalho do cartógrafo. Psicol. Soc., v.19, n.1, p.15-22, 2007.

LIBERMAN, F. O corpo como pulso. Interface - Comunic., Saude, Educ., v.14, n.33, p.449-60, 2010.

LUZIO, C.A.; L'ABBATE, S. A reforma psiquiátrica brasileira: aspectos históricos e técnico-assistenciais das experiências de São Paulo, Santos e Campinas. Interface Comunic., Saude, Educ., v.10, n.20, p.281-98, 2006.

MAFFESOLI, M. Elogio da razão sensível. Petrópolis: Vozes, 2001.

MARTINS, A. Filosofia e saúde: métodos genealógico e filosófico-conceitual. Cad. Saude Publica, v.20, n.4, p.950-8, 2004. 
MERHY, E.E. A perda da dimensão cuidadora na produção da saúde - uma discussão do modelo de assistência e da intervenção no seu modo de trabalhar a assistência. In: CAMPOS, C.R. et al. (Orgs.). Sistema Único de Saúde em Belo Horizonte: reescrevendo o público. São Paulo: Xamã, 1998. p.103-20.

MERLEAU-PONTY, M. Fenomenologia da percepção. São Paulo: Martins Fontes, 1994.

O visível e o invisível. 3.ed. São Paulo: Perspectiva, 1992.

NIETZSCHE, F. O nascimento da tragédia ou helenismo e pessimismo. São Paulo: Companhia das Letras, 2003.

ONFRAY, M. La puissance d'existir. Paris: Grasset, 2006.

PLATÃO. Apologia de Sócrates e Fédon. In: Os pensadores. São Paulo: Nova Cultural, 1999. p. 62-126.

ROSA, G. Grande Sertão: veredas. 19.ed. Rio de Janeiro: Nova Fronteira, 2001.

ROTELLI, F. (Org.). Desinstitucionalização. São Paulo: Hucitec, 1990.

SEPARAVICH, M.A.; CANESQUI, A.M. Girando a lente socioantropológica sobre o corpo: uma breve reflexão. Saude Soc., v.19, n.2, p.249-59, 2010.

SHEETS-JOHNSTONE, M. Putting movement into your life: a beyond fitness primer. S.I.: Kindle Edition, 2010.

The corporeal turn. Exeter: Imprint Academic, 2009.

WACHS, F.; FRAGA, A.B. Educação física em centros de atenção psicossocial. Rev. Bras.

Cienc. Esporte, v.31, n.1, p.93-107, 2009. 
Este estudo objetivou analisar uma experiência de formação do educador físico como profissional de saúde mental, inserido em uma equipe interdisciplinar. A investigação ocorreu no segundo semestre de 2009, em um Núcleo de Apoio Psicossocial, em Santos, estado de São Paulo, Brasil. Foram utilizados, como materiais de análise, os projetos e relatórios produzidos pelos alunos. Os trechos mais significativos destes foram destacados, agrupados segundo tema-chave, e discutidos. Tratou-se de uma coleta de dados qualitativa, que gerou um ensaio reflexivo sobre o tema. Foram identificados três temas-chave: tendência ao sedentarismo entre os usuários; possibilidades de atuação para o educador físico, e aprendizado mútuo e significativo. O educador físico apareceu como um interlocutor no diálogo terapêutico, alguém que veio conversar sobre o corpo ou com o corpo do ser humano acometido pelo sofrimento psíquico. Nossos resultados corroboram a importância deste profissional nesse contexto e descortinam novos horizontes para tal intervenção.

Palavras-chave: Educação Física e treinamento. Formação de recursos humanos. Desinstitucionalização. Saúde mental. Corpo humano.

\section{Physical education in mental health: constructing development from an interdisciplinary perspective}

This study aimed to analyze an experience in developing physical educators as mental health practitioners, within an interdisciplinary team. The investigation took place in the second semester of 2009, in a psychosocial support center in Santos, state of São Paulo, Brazil. The projects and reports produced by the students were used as investigation materials. Their most significant excerpts were extracted, grouped according to their key messages, and discussed. This was qualitative data gathering that generated a reflective essay. Three key themes were identified: a tendency towards a sedentary lifestyle among the users; possibilities of actions for physical educators; and mutual significant learning. Physical educators appeared as interlocutors in the therapeutic dialogue: people who came to talk about the body or to the body of the human being affected by mental distress. Our results corroborate the importance of these professionals in this context and unveil new horizons for this intervention.

Keywords: Physical education. Human resources development. Deinstitutionalization. Mental health. Human body.

\section{La educación física en la salud mental: construcción de una formación interdisciplinaria}

Este estudio tuvo como objetivo analizar una experiencia de formación del educador físico como profesional de salud mental, en un equipo interdisciplinario. La investigación se produjo en 2009, en un Centro de Apoyo Psico-social en Santos, Estado de São Paulo, Brasil. Se utilizaron como materiales de análisis proyectos e informes elaborados por los estudiantes. Los pasajes más significativos fueron agrupados por temas clave, y se discutidos. Se trataba de una recopilación de datos cualitativos, con un ensayo reflexivo sobre el tema. Se identificaron tres temas principales: tendencia a la inactividad entre los usuarios, posibilidades de acción para el educador físico y el aprendizaje mutuo y significativo. El educador físico apareció como un interlocutor en el diálogo terapéutico, alguien que vino a hablar sobre el cuerpo o con el cuerpo de los seres humanos afectados por sufrimientos psíquicos. Nuestros resultados corroboran la importancia de este profesional en tal contexto y descubren nuevos horizontes para la intervención.

Palabras clave: Educación y entrenamiento físico. Formación de recursos humanos. Des-institucionalización. Salud mental. Cuerpo humano. 
